ISSN: 0213-2087 e-ISSN: 2444-7080

DOI: https://doi.org/10.14201/shhcont372019303317

\title{
CONVERSACIONES CON DON MAURO RUBIO SOBRE LA CRISIS DE LA ACCIÓN CATÓLICA ESPAÑOLA
}

\section{Conversations with Don Mauro Rubio on the crisis of the Spanish Catbolic Action}

Feliciano MONTERO GARCÍA $(\dagger)$

Universidad de Alcalá de Henares

Recibido: 13/09/2018 Aceptado: 12/09/2019

RESUMEN: el artículo contiene tres entrevistas que el autor realizó a Mauro Rubio, obispo de Salamanca de 1964 a 1995, sobre la historia de Acción Católica. La tercera está transcrita.

Palabras clave: Acción Católica; Mauro Rubio; Franquismo.

ABSTRACT: the paper contains the three interviews that the author undertook with Mauro Rubio, bishop of Salamanca from 1964 to 1995, on the history of Catholic Action. The third one is transcribed.

Key words: Spanish Catholic Action; Mauro Rubio; Francoism.

En la primavera de 1998 solicité a Don Mauro Rubio, que se encontraba retirado como obispo emérito en el Asilo de las Hermanitas de los Pobres de Salamanca, unas entrevistas a partir de unos cuestionarios que previamente le había pasado sobre su actividad en la Acción Católica española en los años cincuenta y sesenta. Yo tenía muy presente la historia de la AC en los años sesenta, incluida la crisis, que había presentado como investigación original para la cátedra de Historia Contemporánea de la Universidad de Alcalá1. Y, por tanto, tenía muy elaborados esos cuestionarios, especialmente

1. Redactado en 1995, se publicaría como libro en el 2000, Feliciano MONTERO, La Acción Católica y el franquismo. Auge y crisis de la AC especializada. Madrid: UNED, 2000. 
en relación con esos años. En mi conversación (más que entrevista) con D. Mauro, especialmente en la tercera, centrada en la crisis de la AC, se aprecia a veces de forma demasiado intervencionista mi opinión, que parece recabar más la confirmación que una respuesta abierta por parte de D. Mauro. Como si en mi propia pregunta o reflexión estuviera la respuesta. Bien es verdad que el tono de la conversación y sus respuestas escuetas pero rotundas denotan un cierto tono de complicidad en nuestra conversación, al compartir una misma visión de los problemas.

Don Mauro, por su parte, tenía bastante ordenados sus recuerdos, pues había escrito una pequeña autobiografía que se publicaría en 1999. Algunas de las cuestiones recogidas en las entrevistas, especialmente en la primera, están tratadas con más precisión y amplitud, dentro de la brevedad, en su Mi Memoria ${ }^{2}$.

La primera entrevista estuvo centrada en sus primeros estudios y contactos con la Acción Católica, en el tiempo republicano, su experiencia durante la guerra civil, su ingreso en el seminario de Madrid, junto a sus amigos de la Acción Católica, Miguel Benzo y Manuel Aparici, en cierto modo el padrino de ellos; y los primeros años de consiliario nacional de la Juventud Obrera (JOC) a partir del curso 1954-55.

La segunda entrevista, además de volver sobre algunas noticias anteriores, se centraba en su actividad ya en Madrid, primero como consiliario nacional de la JOC entre 1955 y 1960; y luego como consiliario nacional del conjunto de la Juventud de AC (JACE), entre 1960 y 1964, hasta que su nombramiento como obispo de Salamanca en el verano de 1964 le obligó a cambiar totalmente de vida y tareas. La conversación se centró sobre todo en las personas y consiliarios que conoció y con los que colaboró. En primer lugar, su entrañable amigo, compañero y cómplice de la renovación de la Acción Católica, Miguel Benzo, pero también Albert Bonet, Emilio Bellón, y algunos de los primeros consiliarios de la JOC.

La tercera y última entrevista estuvo centrada fundamentalmente en la crisis de la AC de 1966-68, y su interpretación «a posteriori» en el recuerdo; y, más en general, en el clima de la Iglesia y de la Jerarquía de esos primeros años postconciliares, que él vive aislado junto a un grupo muy pequeño de obispos favorables a la renovación conciliar.

De su tiempo de adolescencia y juventud destaca lo que ya había subrayado en sus memorias ${ }^{3}$ : su educación en el Instituto-Escuela, cuyo plan de estudios reproduce como anexo en sus memorias, y su militancia en el Aspirantado y en la Juventud de AC, con cargos en la dirección diocesana y en la nacional. Una educación mixta, excepcional, liberal y católica a la vez, fruto de un pacto familiar. La madre aceptó la elección por parte del padre del Instituto-Escuela a cambio de que acudiera al centro de la Acción Católica. En Mi Memoria dedica un capítulo amplio, dentro de la brevedad del libro, a explicar el espíritu y el método de la educación recibida. Su valoración positiva se

2. Mauro RUBIO, Mi Memoria. Salamanca, 1999.

3. Mauro RUBIO, Mi memoria.... 
confirma en su interés por publicar el programa educativo como apéndice del libro. Pondera especialmente la modernidad de la enseñanza religiosa recibida hasta el punto de enlazarla directamente con el espíritu y la doctrina del Concilio Vaticano II: «se seguía allí un programa bíblico situado en la línea de la Historia de la Salvación y no en el aprendizaje memorístico del Catecismo» ${ }^{4}$. Indudablemente esta formación configura un perfil intelectual católico-liberal bastante excepcional en el mundo eclesiástico de aquel momento. Interesante también es su breve referencia al tiempo de la guerra civil, como asilado, junto a su padre, en la embajada de Paraguay.

Sus recuerdos sobre la inmediata reconstrucción de la Juventud de AC en Madrid, liderada por el mentor Manuel Aparici, al que dedica varias referencias significativas. En la inmediata postguerra, sus dudas entre permanecer en la AC o ingresar en el Opus Dei, a cuyas conferencias asiste un año. Y, finalmente, su ingreso en el Seminario de Madrid, junto con sus amigos Miguel Benzo y Manuel Aparici5.

Tras una breve estancia como párrocos rurales en unos pueblos de la sierra de Madrid, Mauro Rubio y Miguel Benzo — vidas paralelas - hacen una estancia de estudio en la Iglesia española en Roma y en la Universidad Gregoriana. Hasta el verano de 1954, en el que Manuel Aparici, consiliario de la Juventud de AC, les reclama para hacerse cargo respectivamente de la Juventud universitaria y de la Juventud obrera ${ }^{6}$.

En la misma entrevista recuerda su etapa como consiliario nacional de la JOC, entre 1954 y 1960, siendo presidente Eugenio Royo, cuya valía destaca. Recuerda la importancia decisiva de la ayuda del fundador Cardjin. Confiesa que no sabía nada de la JOC y necesitaba enterarse. Recuerda el equipo de consiliarios de la JOC que se fue configurando, los múltiples cursillos de difusión que dirigió, y los congresos internacionales de la JOC en los que participó. Recuerda especialmente el de Río de Janeiro en 1955, en el contexto del Congreso internacional eucarístico, y el Congreso internacional en Roma en septiembre de 1957.

Tan integrado estaba en ese trabajo de crecimiento de la JOC española, que le cuesta aceptar su relevo y nombramiento como nuevo consiliario de la Juventud de AC (JACE) en 1960. Sin embargo, este nombramiento fue decisivo para la transformación de los Centros Parroquiales de Acción Católica general, en movimientos juveniles de AC especializada, por ambientes sociales, siguiendo el modelo ideológico y metodológico de la JOC. Su plena identificación con este modelo (queda clara en la conversación) fue clave para esa transformación y consolidación de la Juventud masculina y femenina de la AC española.

\footnotetext{
4. Mauro RUBIO, Mi memoria..., p. 18.

5. Referencia más amplia y precisa a todo esto en Mi memoria, pp. 31-37

6. En Mi memoria, se amplía las referencias a la etapa de párroco rural, pp. 38-39, y a la etapa romana, pp. 40-43.
} 
La segunda entrevista se centra en el recuerdo de personas, fundamentalmente consiliarios, con los que colaboró. En primer lugar, Manuel Aparici, tan ligado también a Benzo. A ambos dedica una amplia referencia. También, al hilo del recuerdo de Benzo, al Colegio Hispanoamericano Vasco de Quiroga, del que fueron profesores; y a Fernando Urbina, director espiritual en el Vasco de Quiroga; también Albert Bonet, Emilio Bellón, Jose Manuel de Córdoba...

Recuerda el equipo de consiliarios de la JOC que fue configurando en el corto pero intenso quinquenio 1955-60. Al final de la segunda entrevista se alude a la progresiva configuración de un grupo de consiliarios y sacerdotes centrado en una nueva concepción pastoral (misionera) progresivamente crítica con la situación social y política, que anticipa lo que será el conflicto con la Jerarquía en 1966-68.

La interpretación de la crisis que aporta Don Mauro, en la tercera entrevista, confirma en lo esencial lo que yo mismo había analizado y escrito en un libro, publicado dos años después por la editorial de la UNED. Pero algunas respuestas de Don Mauro subrayan mejor algunas hipótesis que yo mismo dejaba algo abiertas:

- El estallido de la crisis en el verano de 1966 como resultado de un proceso iniciado bastante antes, seguido con mucha preocupación por parte de la mayor parte de los obispos, que compartían una mentalidad franquista, precisamente por su deriva de apertura liberal-democrática.

- La importancia del Primado Pla i Deniel como escudo defensor de la AC obrera, adulta y juvenil (HOAC y JOC) y del conjunto de la Acción Católica hasta 1965. No es casual que el conflicto estallara cuando la Comisión Episcopal de Apostolado Seglar (CEAS) tomó el control de la AC que hasta ese momento tenía Pla i Deniel.

- El cerebro de la operación fue Guerra Campos — confirma su valía intelectual y, a la vez, su claro conservadurismo o vinculación con el régimen- pero el responsable fue el arzobispo Morcillo, presidente de la CEAS. No se dejó llevar por Guerra, sino que compartía plenamente su criterio sobre la necesidad de frenar el proceso. El testimonio de Don Mauro, muchos años después, es rotundo.

- Por otra parte, subraya Don Mauro, el criterio de la CEAS era claramente compartido por el conjunto de la Conferencia Episcopal (CEE) de 1966-67. Eso explica que el intento de dialogo obispos-seglares, en el otoño-invierno de 1966-67, previo a la Plenaria de la CEE dedicada monográficamente a la "Crisis" de la AC, fuera inútil, imposible; pues sólo una minoría de obispos, Don Mauro habla de siete frente a cincuenta, eran partidarios del modelo de la AC especializada.

- Es verdad que más adelante, respondiendo a otras preguntas sobre la interpretación de Guerra Campos (politización, infiltración marxista...), y sobre la crisis de identidad y de fe de los militantes, Don Mauro admite que en efecto 
esa crisis habría estallado, pero de otra manera, en otra dimensión. El conflicto de 1966-68 fue fundamentalmente un conflicto político en torno a la naturaleza autoritaria del franquismo, contraria a los valores que promovía la nueva AC especializada.

- Como sabemos la víctima primera y principal del conflicto fue su gran amigo y cómplice, Miguel Benzo, con el que había compartido desde joven su militancia en la Juventud de AC durante la República, su formación en el Seminario de Madrid, su estancia, ya ordenados, en el Colegio Español en Roma, y su vuelta conjunta a España, llamados por su amigo Manuel Aparici, para hacerse cargo respectivamente de la Consiliaría de la Juventud Obrera (JOC) y de la Juventud Universitaria (JUMAC). Y, luego, en los años sesenta, el despliegue de la AC especializada. El nombramiento episcopal de Don Mauro en agosto de 1964 le evitó compartir el sacrificio: el testimonio de D. Mauro es escueto; mantiene el contacto, percibe en la distancia la experiencia durísima que debió vivir su entrañable amigo Benzo, y el proyecto que habían compartido.

- El testimonio de Don Mauro confirma la relevancia de las intervenciones ante el Papa Pablo VI a favor de la AC cuestionada. En su caso, le constan sobre todo las mediaciones del obispo, consiliario de la JOC internacional, Cardjin. Hoy sabemos más de esas mediaciones a través de los diarios de Ruiz Giménez, presidente de Pax Romana, y de Pilar Bellosillo, presidenta del nuevo Consilium Laicis ${ }^{8}$.

El testimonio de Don Mauro es lúcido, claro, rotundo, veraz (confiesa con frecuencia que no recuerda detalles), pero su juicio y valoración son claros. Quizá la brevedad de algunas de sus respuestas tiene que ver con mi tipo de cuestionario, o con el cansancio.

Tercera entrevista a Don Mauro Rubio, el 20-6-989

- Hablemos de los factores que se conjugaron en la crisis de la ACE.

M. La Acción Católica y también la influencia del poder, es decir, que se juntaban los dos factores; el poder nunca aceptó y vio con buenos ojos estas cosas. Estaba siempre, cómo diríamos, con las espadas en alto; y eso influía; pero influía por sí mismo, influía

7. En las entrevistas primera y segunda se refiere abundantemente a su amistad con Benzo y las trayectorias compartidas.

8. Joaquín RUIZ GIMÉNEZ, Diarios de una vida, 1967-1978, Madrid, Cortes Generales, 2013. En el mismo Diario se explica la intervención directa de Bellosillo y RG en la invitación de dirigentes españoles "decapitados» al III Congreso internacional de Apostolado Seglar, con el consiguiente disgusto de la Jerarquía española.

9. Centrada mayoritariamente en la interpretación de la crisis de la ACE. 
en Don Casimiro y sobre todo en Guerra, pero influía no porque viniera del poder, sino porque ellos pensaban que eso era peligroso, que eso era...

- Sí, porque una pregunta que yo me he hecho, y que trasladé a Quevedo ${ }^{10}$ es ¿hasta qué punto los obispos de la Comisión episcopal o de la Conferencia, los más responsables actuaban por propio convencimiento o por la presión del Gobierno? ¿O por las dos cosas?

M. Mira, una parte de convencimiento y otra parte de influencia del poder, la política...

- Ya, ya; pero también porque ellos no estaban realmente de acuerdo con la línea que estaba tomando la Acción Católica,

M. Desde luego; no estaban de acuerdo.

- Pero esa especie de falta de acuerdo con la línea ¿era muy antigua?

M. Sí. Era toda una mentalidad.

- Había empezado, quiero decir, mucho antes, porque la crisis propiamente estalla en el verano del 66 con motivo de las Jornadas nacionales de la Acción Católica Española (ACE) pero estaba muy anteriormente planteada.

M. Pero ya iba preparándose desde antes, desde bastante antes.

- Y por ejemplo, una cosa que también se me ocurre, que indudablemente tuvo que ver mucho, el hecho de que, en fin, ya no estuviera al frente de la Acción Católica el primado, Pla, porque mientras estuvo Pla...

M. Mientras estuvo Pla, la Acción Católica funcionó apoyada por Pla, que era un hombre que en ese aspecto tenía mucha clarividencia. Él era un catalán y había vivido otro tipo de vida y otras costumbres y por tanto, su influencia en la dirección de la Acción Católica fue muy positiva y era el que recibía a consiliarios que venían de fuera, a presidentes. Nosotros fuimos a verle cuando vino Pactiga. Pactiga era entonces el presidente internacional, era un inglés; inmediatamente fuimos a ver al cardenal a Toledo y estuvo hablando con él; era un hombre que diríamos servía de base para todas las actividades de la Acción Católica.

- ¿Pero el cardenal Primado no vio también los problemas que podía haber, de esto del temporalismo, de la politización? ¿No le preocupaba tanto?

M. Seguramente lo vería, pero no lo manifestaba, ni había en él práctica alguna que respondiera a eso.

- O sea, él no frenaba en absoluto la línea.

M. Al contrario, él estaba siempre dispuesto a recibir a todos los dirigentes. Asistía a los congresos. Le llamaban, como Cardjin era el fundador, a él le llamaban el abuelo

10. José Quevedo, fue vicepresidente de la JACE, en funciones de presidente, durante la crisis. Me refiero a una entrevista grabada, por mediador, en el que le pasé un cuestionario, cuando él estaba como sacerdote en Las Palmas de Gran Canaria, publicada en "Los Movimientos de Acción Católica en la crisis del franquismo (1960-1975)", Almogaren, revista del Centro Teológico de Las Palmas, Vol. 30, 2002, pp. 27-58 
de la JOC; al cardenal primado... Recuerdo un Congreso en Toledo que lo presidió él con toda solemnidad con todos los vestidos, las vestiduras cardenalicias y con toda diríamos la fuerza de su convicción.

- Sí, claro, en ese sentido fue muy importante para que la crisis estallara de esa manera, el hecho de que ya no fuera el responsable. A partir del momento que se nombra la Comisión Episcopal de Apostolado Seglar, es la que toma las riendas de la Acción Católica.

M. Es que entonces ya sabemos cuál era la mentalidad de los obispos españoles, ¿no? La mayoría de ellos estaban en esa posición de acercamiento a Franco y de nacionalismo en ese sentido y la Acción Católica era como un tapón a todo eso. Y por eso no sólo se encontró la actitud de la Comisión, sino que respondieron a esa actitud otros muchos obispos.

- A mí una cosa que me llama la atención es que se cree la Comisión Episcopal de Apostolado Seglar dentro del episcopado antes incluso de que se constituya la Conferencia Episcopal. Es muy significativo de la enorme preocupación por la Acción Católica.

M. Sí, bueno, ya venía pasando con otros temas también. Antes de constituirse la conferencia se iban haciendo comisiones.

- Sí es verdad, porque hubo una antes para la pastoral social, que era para los movimientos obreros; precisamente esa existía antes.

M. Y para América, por ejemplo, había una Comisión que se ocupaba de los asuntos... Es decir que venía ya preparándose todo eso.

- Usted es nombrado obispo en el 64, junio o julio.

M. Agosto. Bueno, el nombramiento es en julio, pero vamos...

- Y entonces participa ya en la tercera y en la cuarta sesión del concilio.

M. Y en la penúltima y en la última.

- Sí, eso es. Ya. Es que me pareció ver en algún papel de la Acción Católica, de la Junta, no sé si en el 64 o en el 65, en el tiempo del Concilio, sobre cómo llegan allí los temas de la Acción Católica; los problemas de la Acción Católica llegan allí mismo y parece como que hay presencias, no sé si de Benzo, presencias cualificadas de unos y de otros intentando aclarar qué es lo que pasa. ¿recuerda algo en relación con esto? Que el tema de la crisis o el tema de la Acción Católica ¿se trataran especialmente por los obispos españoles, por grupos, aquí mismo en el tiempo del Concilio?

M. Sí. En el mismo Concilio no sé; porque el Concilio ocupaba todo, era una luz que iluminaba todo; pero desde luego que el tema estaba planteado.

- Y luego, hay también otra cosa que no sé... Otro ángulo de la crisis es el hecho mismo de que se produce coincidiendo o inmediatamente después del propio Concilio, y de que el Concilio aprobara la declaración sobre el apostolado seglar. Y claro, automáticamente digamos los bandos en la crisis tratan de interpretar la doctrina conciliar en su beneficio. 
M. Sí

- ¿Se acuerda de aquello? ¿Cuál cree usted que era la postura de la Jerarquía...?

M. La postura yo creo que era una postura de confusión, porque, claro, por una parte, ha venido el concilio con unas líneas muy nuevas; y por otra parte eso chocaba con otras líneas antiguas y con una manera de ver las cosas; de manera que en ese momento, inmediatamente después del concilio, lo que hubo fue un momento de mucha confusión hasta que se fueron abriendo digamos las puertas y las ventanas y empezó a entrar luz. Pero hubo una situación de confusión, de no saber qué hacer. Porque, como digo, hubo muchos obispos españoles que no estaban de acuerdo con el Concilio ${ }^{11}$.

- No, pero también me quería referir a que me parece que Guerra Campos en su posición y en su libro ${ }^{12}$ y en sus argumentos para justificar su postura en todo lo de la crisis, y claro, él trata de apoyarse en la doctrina conciliar y de hecho, las últimas Jornadas del Valle de los Caídos giran en torno a la interpretación de la naturaleza de la Acción Católica y demás...

M. Eso pasa siempre.

- Eso pasa siempre claro, evidentemente, pero los polémicos temas, el tema del mandato, en fin, la naturaleza de la Acción Católica como dependiente más o menos de la jerarquía la autonomía. Lo que quiero decir es ¿̨hasta qué punto la doctrina conciliar apoyaba eso, daba la razón a unos a otros?

M. Se podía interpretar de las dos maneras. El tiempo ha ido eliminando aspectos y clarificando otros; y entonces la situación actual es muy distinta de toda aquella.

- Usted, en esa época, ya me refiero al momento en el que estalla la crisis, verano del 66, sigue manteniendo mucha relación con Benzo.

M. Con Benzo, siempre.

- Por tanto, la pregunta que le quería hacer es si Benzo le pone al tanto, le trasmite lo que ha pasado; ¿cuál es la trasmisión o la percepción que le hace él en ese momento? Si se acuerda.

M. Bueno, es muy difícil acordarse; pero vamos, la relación continúa estrechamente; y él, pues claro, me confía todo lo que parece que puede ser problemático y me habla de los problemas que él tiene. Así, en concreto no recuerdo.

- Pero para él esta situación en la que se vio total y directamente implicado porque la primera persona descalificada y obligada a dimitir prácticamente es él, como máximo representante, y eso debió ser para él durísimo, me imagino.

11. Creo que en este párrafo se refiere no sólo al tema de la AC sino en general al desconcierto que provoca la nueva doctrina conciliar, por ejemplo, sobre la libertad religiosa.

12. Como se sabe, Guerra Campos explicó su versión de la crisis en una amplia antología de textos y documentos, convenientemente presentados y comentados, J. Guerra Campos, Crisis y conflicto en la Acción Católica española y otros órganos nacionales de apostolado seglar desde 1964. Madrid, Ed. ADUE, 1989. 
M. Sí fue duro porque se había entregado en alma y cuerpo, y esa destitución que le hizo Don Casimiro Morcillo... Don Casimiro era un tipo particular, era un hombre valioso, un hombre activo pero muy influenciado por el pensamiento de entonces; ese pensamiento de que la jerarquía un poco lo era todo y de que había el peligro de la división; y en ese sentido Don Casimiro hizo de verdugo de la Acción Católica, en ese aspecto de cargarse a Miguel Benzo.

- Y la responsabilidad de ese momento, de esa situación de estallido, ¿usted cree que es más o es igual de Don Casimiro o de Guerra Campos?

M. Guerra Campos era el extremo, pero Don Casimiro le apoyaba.

- ¿El brazo fue Guerra Campos?

M. El brazo fue Guerra Campos, pero la autoridad venía de Don Casimiro; entonces el episcopado era muy distinto al de ahora; no había grandes cabezas del episcopado, y Don Casimiro influía poderosamente en todas las cosas del episcopado.

- Es muy difícil interpretar la postura de, (bueno, a primera vista,) de Guerra Campos; porque Quevedo y algunos más me dicen como que les sorprende, por su forma moderna de comportarse al principio como obispo consiliario de la Acción Católica. Les sorprende luego el cambio. ¿Realmente es así; hay un cambio muy grande en su manera? Incluso él tiene una intervención sobre el tema del marxismo muy notable y esto lo he visto en los papeles y tiene mucho (eco) incluso fuera de España. Parece una persona muy al día, muy moderna.

M. Sí, era un hombre que conocía los temas y que los sabía sopesar, pero en cambio siempre su postura fue una postura muy de derechas, muy conservadora. Yo creo que en Guerra influyó mucho Franco. Como él era gallego, había sido profesor en el seminario de Santiago, yo creo que la postura de Guerra era...

- Muy franquista, muy de fidelidad a la persona de Franco.

M. A la persona de Franco, me parece a mí.

- Entonces, ¿él percibe que el tema de la Acción Católica, en fin, las posiciones que toma la Acción Católica son peligrosas para la estabilidad del régimen?

M. Sí, son peligrosas.

- Entonces decide actuar.

M. Él era un hombre muy leído, un hombre preparado pero muy en la línea de derecha, y él era un conservador nato.

- Entonces para usted ¿no fue sorprendente ese cambio?

M. No.

- Porque de ellos, algunos me decían, no sé si Purita Prieto o Pepe Quevedo en la entrevista que tengo grabada, un poco como que les sorprendió ${ }^{13}$.

13. Purita Prieto fue la presidenta de la Juventud femenina de Acción Católica en el tiempo de la consiliaría de Mauro Rubio; Pepe Quevedo, asume la vicepresidencia y luego la presidencia de la Juventud masculina de AC en 1965-67. 
M. Yo creo que no, que se veía venir la cosa muy claramente, me parece a mí; y se explicaba todo con mucha facilidad.

- Una vez que estalla la crisis en el verano, desde el otoño del 66 hasta la asamblea plenaria de la conferencia episcopal febrero o marzo del 67 hay un intento de diálogo ¿no? Yo creo que, en ese intento de diálogo, me imagino que acudirían a usted especialmente los hombres de la Acción Católica, ¿los consiliarios...?

M. Bueno la verdad es que éramos diez o doce obispos los que no estábamos de acuerdo; es que más bien presentaban nuestra acción a votar en contra, a facilitar la conversación de unos con otros; pero eso lo hacían 8 o 10 obispos solamente; el resto votaba siempre en contra.

- Vamos, que el diálogo ese fue prácticamente imposible.

M. Imposible.

- Las posiciones eran muy diferentes.

M. Sí, sí.

- ¿Y Benzo? Inmediatamente que es destituido, enseguida, en septiembre. ¿Él ya se aparta por completo, obedece y se aparta por completo o sigue, hace el seguimiento de todo esto?

M. Sí, se aparta, pero haciendo lo posible para ayudar, para seguir ayudando a la Acción Católica claro. Para él fue muy duro el golpe, pero se aparta oficialmente; en la práctica se aparta, pero después en la teoría él sigue ayudando y sigue dando ánimos a los dirigentes, etc.

- También se me ocurría como tema de conversación, pero así como muy largo, haber entrado un poco en los argumentos que utilizan unos y otros ¿no? Porque a mí me parece que por ejemplo Benzo en el 64, en un artículo en Ecclesia, que luego publicó en un librito... Es un artículo breve pero en el que él trata de responder a las acusaciones que en ese momento, que son prácticamente las acusaciones que luego van a salir; y por otro lado estaría Guerra Campos, que por sus intervenciones y en este último texto que él publicó, pues sería la otra versión ${ }^{14}$.

A mí se me ocurría, pero ese es un tema muy largo, intentar ver los argumentos más en concreto de unos y otros; por ejemplo, el famoso tema del temporalismo, aparte del miedo político que tuvieran. ¿Usted cree que efectivamente dentro de la Acción Católica de los movimientos había un exceso de politización?

M. Bueno, había manifestaciones, porque manifestaciones diríamos de esta postura podía haberlas; era un momento en el que estaba todo tan enfrentado. Sí, puede que hubiera manifestaciones de este problema. Yo quise tratarlo y Miguel Benzo que era

14. Me refiero a Miguel BENZO, "Aclaración de algunas dificultades sobre la actual Acción Católica», en Ecclesia, 20-02-1965, publicado en Pastoral y laicado a la luz del Vaticano II, Madrid, ACE, 1966, pp. 101-110; y a José GUERRA CAMPOS, Crisis y conflicto en la Acción Católica española y otros órganos nacionales de apostolado seglar desde 1964, Madrid, Ed. ADUE, 1989. 
un hombre muy clarividente trataba por lo menos de darle luz al tema y hablarlo con unos y con otros. Claro yo estaba en Salamanca y Salamanca me absorbió mucho.

- Ya, ya me imagino, o sea para usted fue un cambio radical tener que hacer otro tipo de tareas u otro tipo de responsabilidades; y aquello en seguida empezó a estar como lejos, aunque lo siguiera porque estaba muy interesado.

M. No nos quedaba más remedio; la única forma de apoyar eran los votos. Empezó a funcionar la Conferencia Episcopal y empezaron a presentarse esos asuntos. [...] Había siempre un grupo pequeño de votantes que votaban en contra de la línea general, y éstos eran muchos, la mayoría. Gentes procedentes de Acción Católica, obispos jóvenes situados en el ambiente que entonces se vivía...

- Claro, pero era una posición casi testimonial en ese momento.

M. Sí, y que además teníamos la impresión de que no servía para nada. En total si eran 50 obispos, votaban 7 obispos en contra. No tenía importancia.

- Y, por ejemplo, otra de las acusaciones que se hacía era el tema de la parroquia. Que los Movimientos, en el caso concretamente de los juveniles, al haber prácticamente eliminado los Centros parroquiales; que realmente la Acción Católica estaba alejando a los militantes de la parroquia.

M. Sí, eso puede ser bastante verdad, porque los grupos de las parroquias estaban un poco en una línea diríamos muy poco atrevida. Entonces la Acción Católica especializada vino a traer miedo a una renovación de todo eso.

- Otra cuestión que también que me he planteado o que he planteado a la gente: que si de todas maneras, aunque los obispos no hubieran intervenido de esta manera para cortar una determinada línea, si un poco más tarde se hubieran producido crisis internas en la propia Acción Católica; lo que podríamos llamar una crisis de identidad, no ya por razones externas sino por la propia dinámica de... ¿Qué le parece?

M. Sí, se habría producido, seguro.

- O sea que en ese sentido había razones internas para que.... Bueno eso sería otra historia, otra cosas; pero ésta concretamente fue una crisis más bien producida desde fuera ¿no ? Por la cuestión, vamos, política.

M. Sí $^{15}$.

- Le dio mucha importancia. A mí me parece que en ese momento Guerra dio importancia a la Unión Nacional de Apostolado Seglar, la UNAS, que la dirigía al final Miret,

$(\dot{i} \ldots ?)$

- Que si tenía alguna opinión o cómo interpretaba esto; porque da la impresión o a mí me parece que es como si a través de la UNAS quisieran «aguar» un poco o controlar la Acción Católica es decir a través de una institución...

15. Pequeño descanso. Continúa la grabación sobre el tiempo de la crisis; se comienza planteando la posible influencia y significado de la UNAS. 
M. Puede ser, pero no tuvo eficacia ninguna que yo recuerde. La UNAS fue una asociación más.

- Sí, había una gran heterogeneidad, allí había organizaciones parecidas, por ejemplo, las organizaciones de congregaciones de Fecun, o las Vanguardias obreras, de los jesuitas; pero luego otro tipo de asociaciones no tenían nada que ver con el espíritu de la Acción Católica; pero estaban todas mezcladas.

M. Ya, $\mathrm{ya}^{16}$.

- ¿Pero no recuerda? ¿No cree que tuviera alguna incidencia?...

M. Luego, también como resultado de la crisis, una salida a la crisis, aparte de esta acción en la Conferencia, en los votos, era que la Acción Católica se refugió en la diócesis donde podían tener, como aquí, un apoyo, ¿no? Se repliega y se mantiene.

Fue poco a poco generalizándose, a medida que los temas se iban aclarando; poco a poco fue regularizándose la vida de la Acción Católica hasta llegar un momento que ya fue aceptada como tal con todas sus consecuencias, ¿no?

- La verdad es que por otra parte el tiempo en que ocurren estas cosas, el tiempo es muy duro; fue muy duro para muchas personas, pero por otra parte, mirando en perspectiva, fue muy corto; porque la crisis, estamos hablando del 66, y el documento sobre el apostolado seglar del 72 fue totalmente la vuelta ${ }^{17}$.

M. Cuatro años.

- Cuatro o cinco años, cinco años porque es así; el documento del 72 sobre el Apostolado Seglar y la nueva Comisión episcopal estaban en la línea de lo que hasta el 66 se había mantenido ¿es así?

M. Sí. Ya, ya. Yo creo que sí.

- En ese sentido fue un periodo corto. Ahí entra otra cuestión porque es la propia remodelación de la Conferencia Episcopal la que se deshace de una manera muy acelerada, muy rápida.

M. Sí.

- O sea que el grupo que usted decía que era minoría en el 67, ¿dejan de serlo en el 72?

M. ¿Dejan de qué?

- De ser minoría en el 72 y pasan a ser minoría los otros.

16. Da la impresión de que él, no estando ya en la organización interna de la ACE, no conoce o no recuerda esta iniciativa de Guerra Campos, que trataba de agrupar a todas las organizaciones de apostolado seglar, y quizá, de paso, diluir el peso de la nueva AC especializada.

17. Me refiero al documento de la Conferencia Episcopal, "Orientaciones pastorales del Episcopado español sobre el apostolado de los seglares", aprobado en la XVII plenaria, diciembre 1972, en CEAS, El Apostolado seglar en España, Madrid, BAC, 1974, pp. 9-34. El nuevo documento venía a reconocer la importancia de la AC especializada, y trataba de restaurar esa línea, después de la crisis de 1966-68. 
M. Sí, poco a poco se va estableciendo el horizonte y se va consiguiendo una cierta unanimidad en el episcopado en estos temas, pero despacio, claro. En algunos sitios más, en otros menos; claro, es natural que en los sitios donde había industria, donde había obreros, donde había problemas. Eso va a tener mucha más resonancia ¿no?, que en otros en que diría yo no había estas cosas ¿no?, como podía ser Soria.

- Sí, sí y luego también en relación con todo el desarrollo de la crisis también se ha especulado sobre la postura del Papa y en general de la Curia Vaticana ¿no? Parece ser que sí que hubo gestiones directas de algunos dirigentes.

M. Cardjin habló con el Papa del asunto español varias veces y protegió la postura española respecto al Papa. Cardjin tenía una idea muy clara, que sin el Papa y sin la Curia romana no se podía hacer nada; y tenía frecuentes relaciones con ellos; y cuando se plantearon los problemas de la Acción Católica de España, habló en favor de la Acción Católica española.

— ¿Sería en medio de la crisis? ¿o sea después de? [...] No sabe muy bien. Que tenían mucho contacto en ese sentido.

M. Contacto, y que sé positivamente que el tema español fue tratado por Cardjin. Además, entonces es que estaba el problema de qué influencia tenía la Acción Católica, si era francesa o si era belga; y todo eso le llevaba frecuentemente a Roma para hablar con el Papa...

- Eso no lo conocía. Había un problema de que la Acción Católica...

M. Hubo momentos en que la JOC, incluso la internacional, estaba más influida por Francia que por Bélgica, y otros al revés. Y entonces todo esto trajo sus problemas y sus dificultades, y sobre eso Cardjin habló con el Papa, yo creo que repetidas veces.

- También, no sé dónde, leí si Pilar Bellosillo como observadora de las mujeres en el Concilio, no sé si aprovechando esa estancia y la representación que tenía... No, pero eso es después, porque ella sigue siendo presidenta de las mujeres de la internacional de mujeres de la Acción Católica... Me parece que oí algo de que a través de ella había habido una gestión en medio de la crisis, de ir directamente al Papa.

M. Sí, seguramente porque ella estuvo mucho tiempo de presidenta ${ }^{18}$.

- Se podría saber sobre esta gestión, a través de Salvador Sánchez Terán, ${ }^{19}$ quizás porque Salvador Sánchez Terán estaba en la Junta Nacional cuando se planteó.

M. Habría que hablarlo con Salvador porque él recordará muchas cosas, más que yo.

18. Presidenta de la Unión internacional de Mujeres (UMOFC), En el momento de la crisis acababa de ser nombrada presidente de Consilium Laicis, vid. SALAS, M., RODRÍGUEZ DE LECEA, T.: Pilar Bellosillo. Nueva imagen de la mujer en la Iglesia. Madrid: Federación de Movimientos de ACE, 2004.

Los Diarios de J. Ruiz Giménez, confirman esa mediación directa de Pilar Bellosillo con Pablo VI

19. Salvador Sánchez Terán fue presidente de la JACE, hasta 1964, en el tiempo en el D. Mauro era el consiliario nacional 
- Él escribió, no sé si le llegó, o lo leyó en este volumen que publicaron sobre Pablo VI y España, él escribió un texto sobre (la crisis).

M. Sí. Lo conozco ${ }^{20}$.

- ¿Cuál es la posición de estos grupos? ¿Hacen algún tipo de iniciativa, están preocupados o hacen algún seguimiento de alguna manera? Porque quizás el Opus es bastante contrario.

M. Claro.

- Yo no sé en qué medida influye aquí, y si tiene algún tipo de influencia.

M. El Opus es contrario. Es más una línea de derechas, de conservar, y los de la ACNP yo creo que se mantuvieron más o menos neutrales aunque por supuesto mucho más cerca de esto, más cerca de la Acción Católica, estamos hablando que los del Opus.

- Ya, por ejemplo, Herrera Oria. A usted, ¿qué le parece? ¿Cómo cree que entendió la crisis?

M. Bueno, todo esto le tocó ya muy tarde; yo no sé si... Él tenía la intuición clara de la valoración del laicado, eso lo tenía clarísimo; ahora después, la formulación concreta..., eso ya no sé.

- Es que a mí me parece que Herrera Oria también estaba muy preocupado, - por alguna cosa que he leído en su correspondencia-, de la influencia marxista, tanto en España como sobre todo en América y estaba muy obsesionado con ese tema.

M. Eso es típico de la gente del CEU.

- Y en esto, puede coincidir un poco con una de las líneas de interpretación que hace Guerra Campos. Porque Guerra Campos siempre insiste en eso, en que (la evolución de la ACE hacia el compromiso temporal) era una infiltración marxista.

M. Había una incidencia seguramente, claro, algunas veces, pero yo creo que Herrera estaba por encima de todo eso porque era un hombre de mirada profunda y yo creo que, aunque él tuviera sus miedos y sus preocupaciones, yo creo que se daba cuenta de la necesidad de una colaboración seglar, abierta...

- Porque Herrera Oria en la Segunda República fue el que construyó la ACE. Fue el presidente de la Acción Católica; él tenía muy claro lo que era una Acción Católica tipo moderno, pero sin embargo a mí me sorprende que después, ya siendo obispo, parece que, al menos en su diócesis, apenas se desarrolla la Acción Católica, como si él tuviera otras cosas, otros proyectos.

M. Bueno, no. Él era un hombre que le llamaban para muchas cosas y que intervenía en muchos asuntos, y puede ser que eso le impidiera ocuparse de este tema.

- Luego, sin embargo, resulta que él es uno de los miembros de la Comisión conciliar que prepara el decreto del Apostolado de los seglares; o sea que junto a

20. Un pequeño corte o descanso. Continúa la conversación siguiendo el cuestionario, sobre la posición de grupos como el Opus y la ACNP durante la crisis de la ACE y en relación con ella 
otras personas más, (eso también lo han estudiado esta gente de Bolonia ${ }^{21}$ )... Pero, sin embargo, él no participa propiamente en la historia de la AC.

M. No, pero él estaba en ese sentido cerca, aunque tuviera sus temores.

- Así que durante el periodo de la crisis él (Herrera) es obispo aún y está dentro de las comisiones episcopales... ¿Se acuerda cuál es un poco su posición en este momento, en el momento de la crisis?

M. Yo no tenía tampoco mucha relación con él. Alguna vez lo saludé, pero vamos no tenía así...

21. Me refiero a la Historia del Concilio Vaticano II dirigida por G. Alberigo, edición española en Sígueme. 